\section{Cureus}

Received 07/12/2018

Review began 07/13/2018

Review ended 07/13/2018

Published 07/19/2018

\section{(C) Copyright 2018}

Abdelkarim et al. This is an open access article distributed under the terms of the Creative Commons Attribution License CC-BY 3.0., which permits unrestricted use, distribution, and reproduction in any medium, provided the original author and source are credited.

\title{
Osteoma Cutis and Tonsillolith: A Cone Beam Computed Tomography Study
}

\author{
Ahmed Z. Abdelkarim ${ }^{1}$, Scott Lozanoff $^{1}$, Shaimaa M. Abu el Sadat ${ }^{2}$, Ali Z. Syed ${ }^{3}$ \\ 1. Anatomy, Biochemistry \& Physiology, University of Hawaii School of Medicine, Honolulu, USA 2. \\ Department of Oral Radiology, Ain-Shams University, Cairo, EGY 3. Oral Medicine and Diagnostic \\ Sciences, CWRU School of Dental Medicine, Cleveland, USA
}

$\square$ Corresponding author: Ahmed Z. Abdelkarim, ahmedz@hawaii.edu

Disclosures can be found in Additional Information at the end of the article

\section{Abstract}

In this study, we report a rare case of osteoma cutis (OC) and tonsillolith, diagnosed using cone beam computed tomography. The dystrophic calcifications in the face and tonsils were incidentally found during examination of the patient's scan with no relation to the main chief complaint. The diagnosis was OC, combined with dystrophic calcification of the tonsils. It is important to mention that $\mathrm{OC}$ is a rare soft-tissue ossification of cutaneous tissue, typically on the face and clinically asymptomatic. It may be primary but the majority of cases are secondary. Incidental finding of $\mathrm{OC}$ and tonsilloliths on a two-dimensional dental radiograph does not provide sufficient information concerning the location of these calcifications. Thus, cone beam computed tomography (CBCT) provides critical information for the diagnosis of asymptomatic OC lesions not available through any other means of clinical detection.

Categories: Otolaryngology, Radiology, Miscellaneous

Keywords: osteoma cutis, diagnostic imaging, tonsilloliths., cone beam

\section{Introduction}

Osteoma cutis (OC) and tonsilloliths are soft-tissue calcifications in the head and neck region that result from the deposition of minerals at specific sites and may be of pathological, agerelated or idiopathic origins [1]. OC is a rare, benign ectopic presence of calcification within the dermis or epidermis with non-invasive behavior [2]. It is indicative of Albright syndrome, where mesenchymal cells secrete a matrix that becomes calcified and differentiates into focal bone in the soft tissues. The most common form, about $85 \%$ of the detected cases, is secondary to long duration conditions such as acne, chronic inflammatory dermatoses, or scarring [1]. Previous studies reported that OC manifests a broad spectrum of features; [2-5] it has been described clinically as a normochrome skin over subcutaneous non-compressible papules with a higher incidence in females and/or in patients that have been previously diagnosed with acne vulgaris $[6]$.

Another example of soft-tissue calcification is tonsillar stones or tonsilloliths. These lesions occur as white or yellow densifications in tonsillar crypts that originate from microorganism and tissue debris retention in the crypts of palatine tonsils [7]. Tonsilloliths arise as calcifications resulting from repeated inflammation of the tonsillar crypts during recurrent tonsillitis without gender prevalence [8].

In dentistry, routinely performed dental radiographs can capture the lesion most commonly in the lips and cheek regions; however, due to difficulty in localization, interpretation of OC cases 
has always been challenging especially using conventional imaging. CBCT, with its 3D software based volumetric reconstruction and multiplanar evaluation with a distortion-free image, offers an important clinical tool facilitating detection and diagnosis of these calcific lesions [9]. Cone beam computed tomography (CBCT) is particularly useful since a typical craniofacial scan depicts areas beyond one specific region of interest thus facilitating and enabling incidental findings. For example, Safi et al. recently reported the prevalence of $\mathrm{OC}$ as an incidental finding detected on CBCT to be $2.27 \%$ [10].

The present case reports OC in a combination of tonsillar stones. This condition was an incidental finding identified during a CBCT scan evaluation, apart from the main chief complaint of the patient without related symptoms. The purpose of this presentation is to underscore the importance of $\mathrm{CBCT}$ for evaluating OC lesions by the dental professional using three-dimensional radiography.

\section{Case Presentation}

A 33-year-old male presented to be admitted as a patient at Case Western Reserve University School of Dental Medicine clinic in Cleveland, Ohio for the purpose of obtaining dental implants. However, the patient complained of pain in his upper jaw bilaterally. His medical history was free from systemic diseases but indicated a past history of acne and recurrent tonsillitis. His vital signs were recorded as 126/85 mmHg blood pressure, pulse of $103 \mathrm{bpm}, 15$ respirations per minute, height $6.1 \mathrm{ft}$, weight $196 \mathrm{lb}$, a calculated body mass index (BMI) of 23.71. No other medical conditions were listed, and the patient did not report taking any medications.

Upon intraoral examination, badly decayed upper right second molar and highly restored left second molar were noticed with pain on percussion. Dental periapical lesions were suspected. The patient was referred to a private dental imaging center for imaging of the jaws for implant treatment planning. A CBCT scan was taken using a Planmeca Promax X-ray (Planmeca, Helsinki, Finland) unit. Upon reviewing the scan, multiple small nodules of high density were identified as an incidental finding during the interpretation of the patient's scan (Figure 1). 


\section{Cureus}

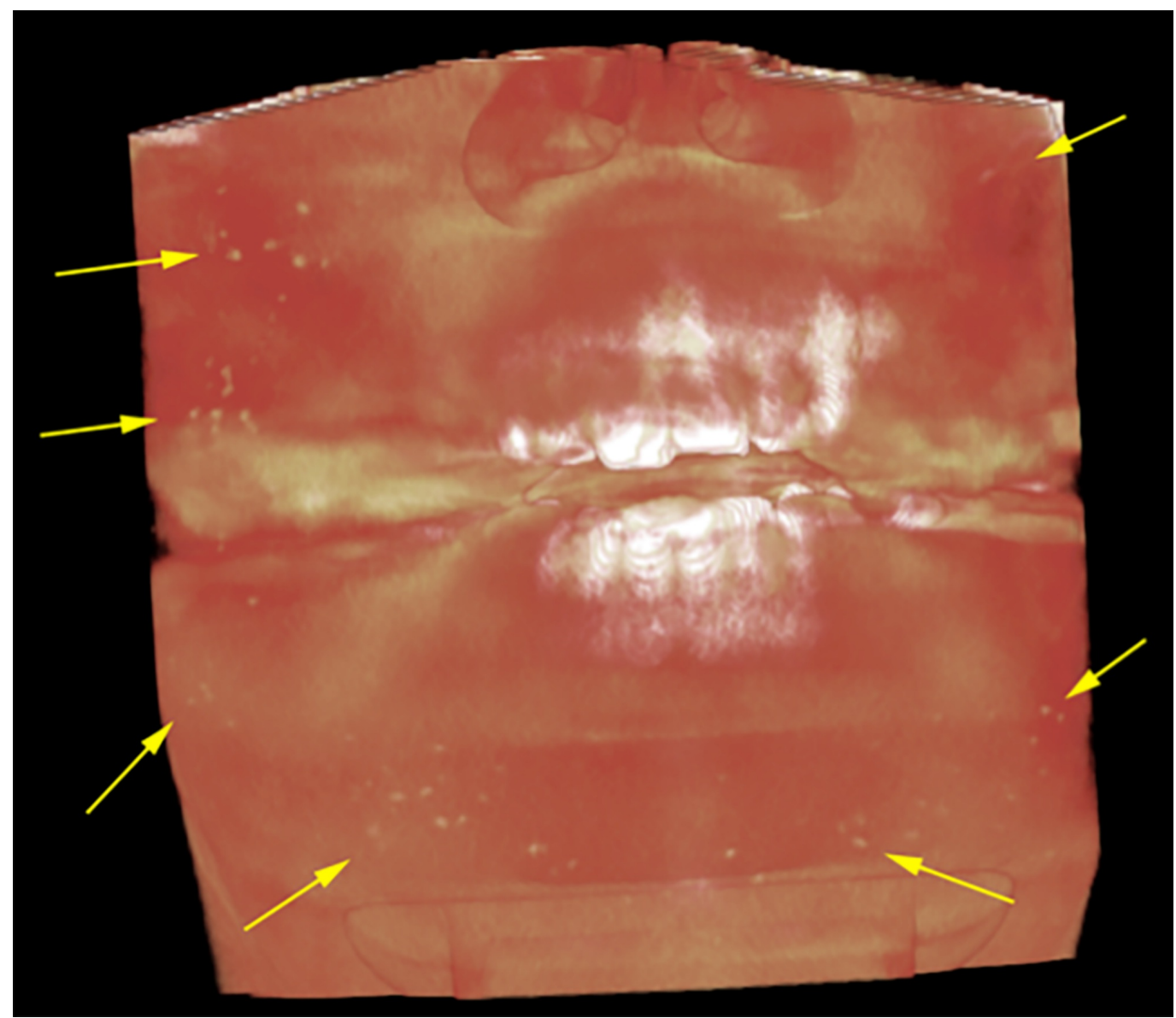

FIGURE 1: Volumetric rendering of CBCT scan of OC. Soft tissue rendering shows multiple small nodules of high density spread in the cheeks, lips and chin regions indicated by yellow arrows.

The nodules appear to be dispersed among the layers of the face, which were clearly displayed in more than coronal and axial cuts (Figure 2).

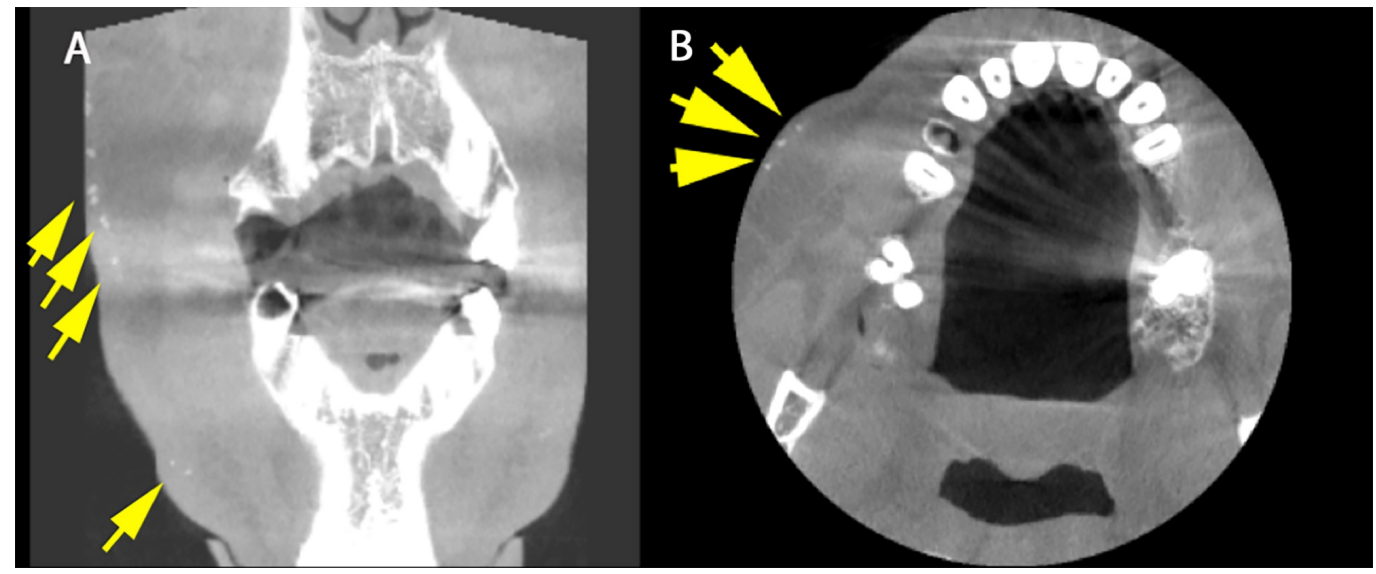

FIGURE 2: Axial and coronal sections. A) Coronal cut showing multiple radiopaque masses along the dermal layer lateral to 


\section{Cureus}

the buccinator muscle indicated by yellow arrows. B) Axial cut with a yellow arrows showing 3 small concentric nodules in the buccal cheek

The multiple nodules were consistent with the miliary type of OC and his past history of acne as a teenager. The palatine tonsils, in addition, revealed radiopaque masses bilaterally, but more numerous and prominent on the left side. The calcifications were also consistent with the patient history of recurrent tonsillitis as tonsillar stones (tonsilloliths) (Figure 3). The patient was advised to visit his dentist and receive a panoramic radiography regularly to follow up the spread of the calcification, especially to the blood vessels.
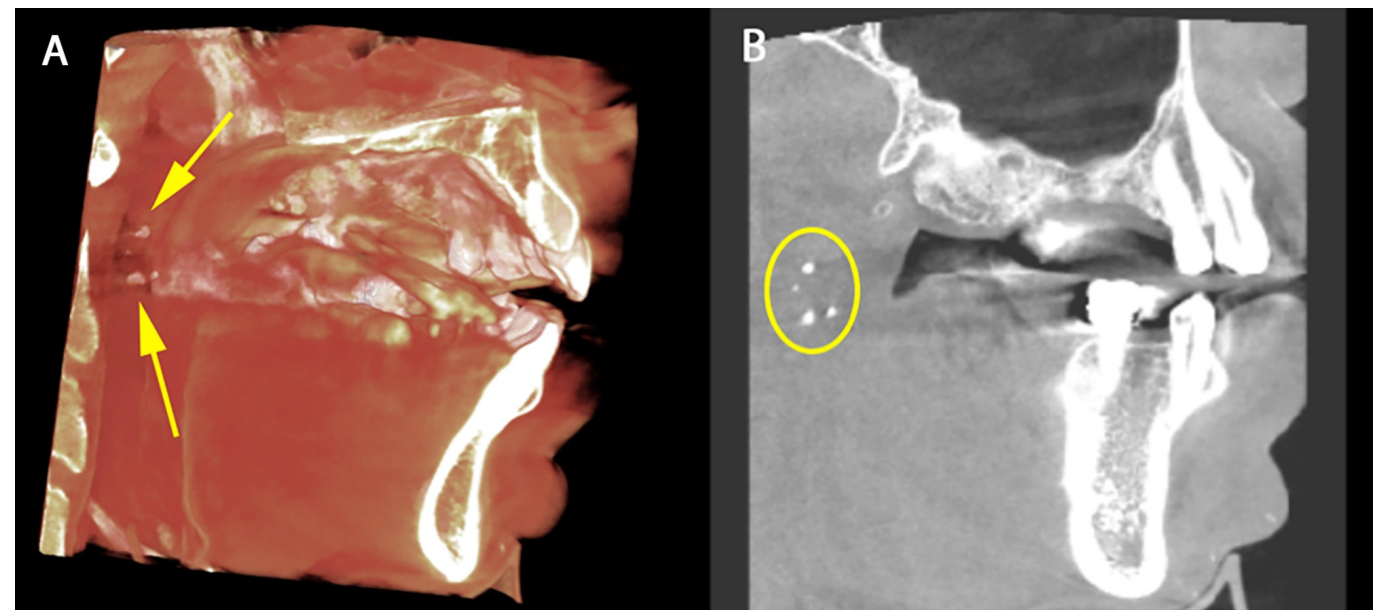

FIGURE 3: Tonsillar stones in the palatine tonsils. A)

Volumetric rendering displaying multiple small radiopaque masses in the left palatine tonsils consistent with tonsilloliths (yellow arrows). B) Sagittal section displaying multiple small radiopaque masses in the left palatine tonsils consistent with tonsilloliths (yellow circle).

\section{Discussion}

The case reported in this study is that of OC with tonsilloliths, diagnosed using CBCT. OC is a benign and rare condition in which soft-tissue ossifications occur in the dermis layer of skin. The disease is categorized into primary or secondary forms. Primary forms are characterized by the lack of any history that would lead to predispose bone deposition within the layers of the skin, such as trauma or cutaneous disease, and accounts for $15 \%$ of OC cases [11]. Secondary $\mathrm{OC}$, on the other hand, is associated with a known predisposing factor such as inflammation, trauma, neoplastic changes, nevi, or venous stasis [12-13].

Theories, ranging from hamartomas to nevoid tumors, have been associated with the etiology and pathogenesis of OC [14]. Also, it has been advocated that OC is the result of osteoblastic metaplasia of mesenchymal cells following prolonged inflammation associated with common acne or Botox injecting sites in the face but the specific mechanism remains unknown and debated [14]. 
Clinically, OC presents with different asymptomatic forms. It may present as single or multiple papules, nodules, or plaques or as miliary lesions [9]. The lesions are hard bony structures on palpation and show discoloration of the skin in occasional cases [6]. In radiographs, the lesions have a small, smoothly outlined hyperdense spots which are donut- or snowflake-like in shape and vary in size from $0.1 \mathrm{~cm}$ to $5.0 \mathrm{~cm} \mathrm{[9].}$

Understanding the radiographic presentation of OC facilitates definite identification since several imaging features may be mimicked by other soft-tissue calcification conditions confounding accurate diagnosis. For example, myositis ossificans, calcinosis cutis, osteoma mucosae, and dermal fillers may have the same radiographic manifestations [9, 15-16]. Other condition such as calcified phleboliths in hemangiomas, surgical clips, wires, or sutures placed for procedures such as face-lifts may be confused with OC [17-18]. Medical history and imaging findings typically provide complementary information facilitating an accurate diagnosis [19].

In this case report, OC is combined with tonsilloliths. The specific etiology and pathogenesis of tonsilloliths remain unknown, however, it is generally agreed that unresolved tonsillitis is the main cause [8]. Recurrent episodes of inflammation may cause fibrosis at the openings of the tonsillar crypts, causing microorganism and epithelial debris accumulation that leads to retention cysts formation then subsequent calcification [20]. This explanation is consistent with a patient history of recurrent tonsillitis.

Differential diagnosis of tonsilloliths includes mostly sialoliths, lymph node calcification, and phleboliths. CBCT images provide bilateral views of the jaw and are useful to determine and differentiate the locations of these calcifications [9].

Correct diagnosis of the different types of soft-tissue calcifications requires sufficient knowledge from the dental professional. Clinical management of these conditions must be based on the patient's medical history and symptomatology [19]. Volumetric imaging has revolutionized the dental practice by making it possible to visualize structures in all three dimensions. With this privilege comes the responsibility of recognizing every small detail captured within these images. It is vital to examine the entire CBCT volume for any abnormalities and to recognize and report incidental findings. This will lead to more accurate diagnosis, appropriate management, and prompt referral of patients and improved dental health [20].

\section{Conclusions}

In this case report, we presented a rare case of OC, combined with tonsillolith using CBCT as a diagnostic method. The general dentist, using three-dimensional dental radiography, typically encounters soft-tissue calcifications. Based on careful examination of the patient's scan, incidental findings are adding to the value of using CBCT as a diagnostic imaging tool and ultimately, improved patient health.

\section{Additional Information Disclosures}

Human subjects: Consent was obtained by all participants in this study. Conflicts of interest: In compliance with the ICMJE uniform disclosure form, all authors declare the following: Payment/services info: All authors have declared that no financial support was received from any organization for the submitted work. Financial relationships: All authors have declared that they have no financial relationships at present or within the previous three years with any organizations that might have an interest in the submitted work. Other relationships: All authors have declared that there are no other relationships or activities that could appear to 
have influenced the submitted work.

\section{References}

1. Price JB, Thaw KL, Tyndall DA, Ludlow JB, Padilla RJ: Incidental findings from cone beam computed tomography of the maxillofacial region: a descriptive retrospective study. Clin Oral Implants Res. 2012, 23:1261-1268. 10.1111/j.1600-0501.2011.02299.x

2. Duarte IG: Multiple injuries of osteoma skin in the face: therapeutical least invasive in patients with acne sequela - case report. An Bras Dermatol. 2010, 85:695-698. 10.1590/S036505962010000500016

3. Aneiros-Fernandez J, Husein-ElAhmed H, Orgaz-Molina J, O'Valle Ravassa F, Arias-Santiago S: A man with infiltrated and indurated plaque on the forehead . Dermatol Online J. 2010, 16:12. Accessed: 2010 Jun 15: https://escholarship.org/uc/item/4kt443v0.

4. Riahi RR, Cohen PR: Multiple miliary osteoma cutis of the face after initiation of alendronate therapy for osteoporosis. Skinmed. 2011, 9:258-259.

5. Thielen AM, Stucki L, Braun RP, et al.: Multiple cutaneous osteomas of the face associated with chronic inflammatory acne. J Eur Acad Dermatol Venereol. 2006, 20:321-326. 10.1111/j.1468-3083.2006.01425.x

6. Bouraoui S, Mlika M, Kort R, Cherif F, Lahmar A, Sabeh M: Miliary osteoma cutis of the face . J Dermatol Case Rep. 2010, 5:77-81. 10.3315/jdcr.2011.1082

7. Dykes M, Izzat S, Pothula V: Giant tonsillolith - a rare cause of dysphagia . J Surg Case Rep. 2012, 2012:4-4. 10.1093/jscr/2012.4.4

8. Mesolella M, Cimmino M, Di Martino M, Criscuoli G, Albanese L, Galli V: Tonsillolith. Case report and review of the literature. Acta Otorhinolaryngol Ital. 2004, 24:302-307.

9. White SC, Pharoah MJ: Oral Radiology: Principles and Interpretation by Stuart White and Michael Pharoah. Mosby (ed): Elsevier, St. Louis; 2005. 10.1016/j.tripleo.2004.10.015

10. Safi Y, Valizadeh S, Vasegh S, Aghdasi MM, Shamloo N, Azizi Z: Prevalence of osteoma cutis in the maxillofacial region and classification of its radiographic pattern in cone beam CT. Dermatol Online J. 2016, 22:1. Accessed: June 18, 2018: https://www.ncbi.nlm.nih.gov/pubmed/26990467.

11. Cottoni F, Dell' Orbo C, Quacci D, Tedde G: Primary osteoma cutis. Clinical, morphological, and ultrastructural study. Am J Dermatopathol. 1993, 15:77-81.

12. Altman JF, Nehal KS, Busam KJ, Halpern AC: Treatment of primary miliary osteoma cutis with incision, curettage, and primary closure. J Am Acad Dermatol. 2001, 44:96-99. 10.1067/mjd.2001.108377

13. Conlin PA, Jimenez-Quintero LP, Rapini RP: Osteomas of the skin revisited: a clinicopathologic review of 74 cases. Am J Dermatopathol. 2002, 24:479-483. 10.1097/00000372-200212000-00004

14. Ghabanchi J, Haghnegahdar A, Khojastehpour L, Ebrahimi A: Frequency of tonsilloliths in panoramic views of a selected population in southern Iran. J Dent (Shiraz). 2015, 16:75-80.

15. Goldminz D, Greenberg RD: Multiple miliary osteoma cutis. J Am Acad Dermatol. 1991, 24:878-881. 10.1016/0190-9622(91)70138-r

16. Burgess CM: Principles of soft tissue augmentation for the aging face . Clin Interv Aging. 2006, 1:349-355. 10.2147/ciia.2006.1.4.349

17. Valiyaparambil J, Rengasamy K, Mallya SM: An unusual soft tissue radiopacity--radiographic appearance of a dermal filler. Br Dent J. 2009, 207:211-212. 10.1038/sj.bdj.2009.764

18. Keestra JA, Jacobs R, Quirynen M: Gold-wire artifacts on diagnostic radiographs: A case report. Imaging Sci Dent. 2014, 44:81-84. 10.5624/isd.2014.44.1.81

19. Missias EM, Nascimento E, Pontual M, Pontual AA, Freitas DQ, Perez D, Ramos-Perez F: Prevalence of soft tissue calcifications in the maxillofacial region detected by cone beam CT . Oral Dis. 2018, 24:628-637. 10.1111/odi.12815

20. Alhazmi D, Badr F, Jadu F, Jan AM, Abdulsalam Z: Osteoma cutis of the face in CBCT images . Case Rep Dent. 2017, 2017:8468965. 10.1155/2017/8468965 